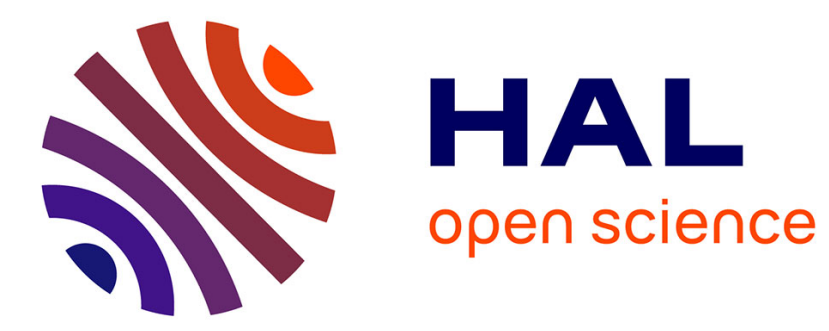

\title{
Ontology-Based Backward Learning Support System
}

\author{
Masao Okabe, Masashi Umezawa, Takahira Yamaguchi
}

\section{To cite this version:}

Masao Okabe, Masashi Umezawa, Takahira Yamaguchi. Ontology-Based Backward Learning Support System. 11th IFIP World Conference on Computers in Education (WCCE), Jul 2017, Dublin, Ireland. pp.398-408, 10.1007/978-3-319-74310-3_41. hal-01762892

\section{HAL Id: hal-01762892 \\ https://hal.inria.fr/hal-01762892}

Submitted on 10 Apr 2018

HAL is a multi-disciplinary open access archive for the deposit and dissemination of scientific research documents, whether they are published or not. The documents may come from teaching and research institutions in France or abroad, or from public or private research centers.
L'archive ouverte pluridisciplinaire HAL, est destinée au dépôt et à la diffusion de documents scientifiques de niveau recherche, publiés ou non, émanant des établissements d'enseignement et de recherche français ou étrangers, des laboratoires publics ou privés. 


\title{
Ontology-based Backward Learning Support System
}

\author{
Masao Okabe ${ }^{1}$, Masashi Umezawa², Takahira Yamaguchi ${ }^{3}$ \\ ${ }^{1}$ Department of Management and Communication, Faculty of Life Design, Tohoku \\ Institute of Technology, Japan \\ ${ }^{2}$ SoftUmeYa, LLC., Japan \\ ${ }^{3}$ Department of Administration Engineering, Faculty of Science and Technology, Keio \\ University, Japan \\ okabemasao@tohtech.ac.jp, ume@softumeya.com, yamaguti@ae.keio.ac.jp
}

\begin{abstract}
One of the main goals of introductory courses of a university is to make freshmen well prepared for subsequent intermediate courses. But nowadays it becomes difficult because academic skills of freshmen differ very much. To resolve this problem, this paper proposes an ontology-based backward learning support system called EduGraph. If a student cannot understand some learning item, EduGraph, based on its ontology, suggests him or her prerequisites for understanding the item, and he or she can learn them using EduGraph. For the student, to understand the incomprehensible item can be a short-term goal because prerequisites for it are suggested, and he or she is expected to keep intrinsically motivated to understand the item. EduGraph can also support a student to organize what he or she learns into his or her integrated knowledge, because its ontology is based on a welldesigned upper ontology for learning and can organize learning items properly. Actual applications to several introductory courses from 2015 suggest that EduGraph is effective.
\end{abstract}

Keywords: Ontology, concept map, backward learning, intrinsic motivation

\section{Introduction}

More than half of students go on to higher education in Japan. That means that academic skills of freshmen vary very much and unfortunately some of them do not have academic skills necessary for learning at a university. One of the main objectives of introductory courses for freshmen is, hence, to make students with different academic skills well prepared for subsequent intermediate courses. But, under the actual environment where one teacher has to teach a large number of students in a large classroom, this is hardly achieved. To resolve this problem, this paper proposes an ontology-based backward learning support system called EduGraph.

The structure of this paper is as follows. Section2 reviews related works. Section3 and 4 present the proposal. Section5 describes tentative evaluation. Finally, section 6 summarizes the proposal and points out some future works. 


\section{Related Works}

\subsection{Motivation and Short-term Goal}

Motivation is a key factor for successful learning. There are two kinds of motivation, intrinsic motivation and extrinsic motivation. According to Ryan and Deci [1], intrinsic motivation is defined as the doing activity for its inherent satisfactions rather than for some separable consequence, and extrinsic motivation is a construct that pertains whenever an activity is done in order to attain some separable outcome. Ideally, intrinsic motivation is more important, but there is no general way to make all students motivated intrinsically because intrinsic motivation exists in the nexus between a student and a task [1]. Therefore, to make a student intrinsically motivated, setting a task or a goal appropriate to the student is important. Stipek suggests that an appropriate level of challenge can be achieved by adjusting goal for students with varying skill levels and also that to avoid discouragement on a long-term task, it is better to set short-term goals [2].

\subsection{Backward Design and Backward Learning}

Backward design is an instructional design method developed by Wiggins and McTighe [3]. Its point is "the end in mind first". Teachers tend to focus on lessons and textbooks without a clear image of desired results. In backward design, desired results are determined first, before teaching method or lessons are considered. Its advantage seems obvious since the objectives of a course are to get desired results.

This "the end in mind first" policy is now being applied also to instructions themselves. For example, "Backwards Learning Organizer" [4] is a template with which students clarify their goals first. Although the basic principle "the end in mind first" is the same, the meaning in backward learning as instructions is substantially different from the one in backward design. It seems mainly to help students clarify their short-term goals and intends to keep students intrinsically motivated. In some domains, there are several "the end in mind first" instructional practices. For example, in the domain of proof problems at high-school mathematics, Sasaki [5] shows that a proof by backward inference is more understandable to students than one by forward inference. Sasaki claims that a proof by backward inference fits students' thought processes better than one by forward inference. In this case, "the ends in mind first" is a short-term goal and also help student intrinsically motivated.

\subsection{Concept Map and Ontology}

A concept map is a graph with nodes that are concepts to be learnt and with links among them. It was developed by Novak [6] in 1972, based on the learning psychology by Ausubel [7]. That is, it supports meaningful learning, and not mere rote learning, by helping a learner organize his or her cognitive structure to encourage a deep level of integrated knowledge [8]. Integration of knowledge is important, but it is also true that a concept map has limitations for this purpose. That is, there are many concept maps, but there is no integrated concept map.

An ontology is defined as "an explicit specification of a conceptualization" [9]. More intuitively saying, similar to a concept map, an ontology at least represents 
concepts and relations among them in some domain, and it is often represented by a graph with concepts as its nodes and with links between them. Compared to a concept map, an ontology is more general-purpose, but if an ontology is applied to learning, it can be very similar to a concept map. Actually, there are many proposals of learning methodologies or learning support systems using ontologies, including [10, 11, 12]. In the domain of history, Muroya et al. [13] propose self-exploratory learning based on a learner's interest, using Linked Open Data (hereafter, LOD), which is a kind of ontology. In this LOD, nodes are historical events, places where events occurred, persons who engaged in events, and so on, and these nodes are linked each other. Following links of an event, based on his or her own interest, a learner can get deep understanding of the event. This is very similar to what a concept map intends to do. In addition, this LOD may make a learner intrinsically motivated to understand the event, which is a short-term goal.

An ontology has a similar problem as a concept map. There are many ontologies in many domains, which are often overlapped. But, they are not integrated and, even worse, they are sometimes inconsistent. To resolve this problem, several upper ontologies are developed [14 - 18]. An upper ontology is a top-level domain-neutral ontology to be a basis of more specific domain ontologies. If domain ontologies are developed based on the same upper ontology, they are expected to be consistent each other and to be integrated based on the upper ontology. Unfortunately, there is still no consensus on what an upper ontology should be used. But, apparently, BFO [14] is the most widely used upper ontology. It was originally developed as a basis of biomedical ontologies, but now it intends to be a basis of most of ontologies, not limited to biomedical ones, and aims to promote consistency in description of scientific data and then to promote interoperability of scientific data in electric format among computers [19].

\section{EduGraph}

EduGraph is a simple ontology-based learning support system, which supports backward learning, giving a short-term goal for each student, and motivating him or her intrinsically. It can be used by a teacher in a classroom in a usual manner and also by students themselves outside a classroom.

EduGraph mainly consists of two parts. One is a slide part and the other is an ontology part. In the slide part, a teacher can easily create slides in Markdown [20], a simple markup language, and upload them on the Web. Both a teacher and students use them via a browser just same as usual slides. Slides for one class usually contain several learning items, each of which are normally explained by one to at most several slides and can be a short-term goal. A teacher can construct slides for one class, combining sets of slides for several learning items in any order.

In the ontology part, EduGraph ontology structures all learning items as its nodes with several types of relationships among them. Each node has a link to slides that explain the learning item. The structure of EduGraph ontology is simple and can be represented fully by a graph. A teacher can easily expand EduGraph ontology using Neo4j [21], a graph database. Using the ontology part, for any learning item, a student 
can easily access slides that explain it, by tapping or clicking the corresponding node of EduGraph ontology by a smartphone or a PC.

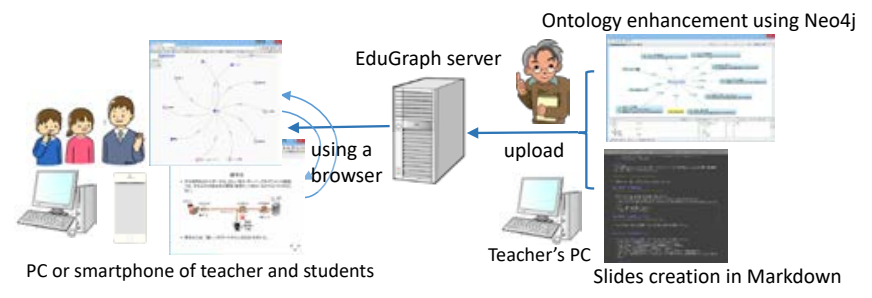

Fig. 1. Overview of EduGraph

\section{$4 \quad$ EduGraph Ontology}

\subsection{Relationship Type}

EduGraph ontology is a key component of EduGraph and has two important roles. One is to navigate a student to backward learning if he or she still has difficulty in understanding what he or she has learnt, and the other is to help a student incorporate what he or she has learnt into his or her integrated knowledge. For these purposes, EduGraph ontology currently has four types of relationships as shown at Table 1. All of them are very popular relationship types, except that EduGraph uses general terms for students who are not familiar with ontologies. For example, Edugarph uses "part”, rather than "is_part_of". But, "part" of EduGraph is extended from usual "is_part_of". "Is_part_of” is usually applied to physical things such as "a piston is_part_of an engine”. From the point of learning, this means that, to understand an engine, it is necessary to understand a piston. From this point, "part" of EduGraph is extended and can be applied to any learning item, not limited to one about a physical thing. If learning item A is "part" of learning item B, it means that, to understand learning item $\mathrm{B}$, it is necessary to understand learning item $\mathrm{A}$, that is, learning item $\mathrm{A}$ is a prerequisite for learning item $\mathrm{B}$. If a student does not understand learning item $\mathrm{B}$, even with slides that explain it, he or she goes back to learning item A and learn it. For this learner, learning item B is a short-term goal, and he or she can understand it, with backward learning of learning item $\mathrm{A}$.

For the purpose of getting integrated knowledge, all the relationship types, including "part", are used. But, to support integration of any learning items, EduGraph ontology needs to be based on a well-designed upper ontology.

Table 1. Relationship types of EduGraph ontology

\begin{tabular}{lll}
\hline \hline Relationship type & \multicolumn{1}{c}{ Notation } & \multicolumn{1}{c}{ Meaning } \\
\hline subclass & A - subclass $->B$ & B is a subclass of A. \\
example & A - example $->$ B & B is an example (instance) of A. \\
part & A - part $->$ B & B is part of A. \\
related item & A - related item -> B & B is related to A. \\
\hline \hline
\end{tabular}




\subsection{Upper Ontology of EduGraph Ontology}

Originally, EduGraph ontology was planned to be developed based on BFO. But, BFO was not suitable for an upper ontology of EduGraph ontology. Firstly, objectives are different. The objectives of BFO are interoperability of scientific data in electric format among computers, but the objectives of EduGraph ontology are to navigate a learner. Secondly, domains are different. BFO now intends to be a domain-neutral upper ontology. But, BFO seems to be slightly influenced by its origin as a basis of biomedical ontologies. From the point of learning, there are a lot of so-called abstract concepts to be learnt, but BFO only has a class called "Generically dependent continuant" (see Fig. 2) for them, probably because they are not important to biomedical ontologies.

Therefore, EduGraph ontology has its own upper ontology. It is somewhat different from BFO because of the reasons above. Basic structure of the upper ontology of EduGraph ontology, in contrast to BFO, is as follows.

Identification of Learning Item. To design an ontology, identification is a big issue. For example, it is not easy to decide how to treat Beethoven Symphony No.5. In some situation, Beethoven Symphony No.5 may mean its score, and in another situation, it may mean its performance. Hence, usually, from an ontological point of view, Beethoven Symphony No.5 as a score and as a performance should be distinguished from each other. BFO is a high-level upper ontology and does not influenced directly by this issue but takes this position. From the point of learning, in most cases, a learner learns all aspects of Beethoven Symphony No.5, including its score and its performance. Hence, EduGraph ontology has one node for Beethoven Symphony No.5 as one learning item, instead of having different nodes as a score and as a performance.

Universals and Particulars. One of the top-level dichotomies is universals and particulars. BFO does not have this top level dichotomy and only categorizes universals. Particulars are out of the scope of BFO, because BFO is to provide universals that can classify particulars for its objectives. EduGraph ontology does not have this top level dichotomy either and mainly structures universals because usually a learning item is a general thing, that is, a universal. But, sometimes, a particular may be a learning item, or even if it is not a learning item, it may be important if the particular as an example helps a learner understand a general thing (a universal). In that case, EduGraph ontology classifies the particulars under the universal as its instances.

Structure. EduGraph has the same top-level dichotomy as BFO, except that EduGraph uses general terms "Static thing" and "Dynamic thing", instead of "Continuant" and "Occurent", which BFO uses. BFO has three direct subclasses of "Continuant" called "Independent continuant”, "Generically dependent continuant", and "Specifically dependent continuant", as shown in Fig. 2. Generally speaking, "Independent continuant" is a class of entities that exist independently, whether 
tangible or not, and "Dependent continuant" is a class of entities that exist dependent on another entity. BFO distinguishes "Generically dependent continuant" from "Specifically dependent continuant". The latter is a class of entities that exist dependent on another entity which cannot be changed, and its typical subclass is "Quality". On the other hand, the former is a class of entities which exist dependent on another entity, which can migrate one entity to another, and its typical subclass is "Information", which BFO itself does not have. Intuitively saying, a so-called abstract concept has many representations, and each representation is a specifically dependent continuant and this abstract concept is a generically dependent continuant. An abstract concept and its representations are strictly distinguished in BFO. But, from the point of learning, it is rarely necessary to distinguish between them, because, generally speaking, what should be learnt is not a representation but its meaning. Hence, in EduGraph ontology, "Specifically dependent continuant” and "Generically dependent continuant" are merged to just "Dependent thing" and the difference between a representation and its semantics is ignored. Thus, in EduGraph ontology, "Static thing” has two direct subclasses called "Independent thing” and "Dependent thing”, as shown in Fig. 3.

BFO has two direct subclasses of "Independent continuant" called "Material entity" and "Immaterial entity". The interesting thing is that "Immaterial entity" includes only boundary, region and site (space) and that a so-called abstract concept is not an immaterial entity. This is partially because, philosophically, BFO stands on realism and not conceptualism, and partially because BFO classifies an abstract concept as a generically dependent continuant. Boundary, region and site are important in biology, but from the point of learning, compared to many abstract concepts to be learnt, boundary, region and site are not important. Therefore, in EduGraph ontology, "Independent thing” has two direct subclasses called "Tangible thing" and "Intangible thing", and "Tangible thing" is almost the same as "Material entity" in BFO, but "Intangible thing” is much broader than "Immaterial entity" in BFO and includes abstract concepts, or some portion of "Generically dependent continuant” in BFO.

Treatment of Role. From an ontological point of view, it is important to decide what subclasses of an entity are appropriate. For example, usually, man and woman are subclasses of person, but lawyer and teacher are not subclasses of person, because if a person is a lawyer at some time, he or she may cease to be a lawyer and may become a teacher at another time. Lawyer and teacher are usually treated as roles that person can have or that depend on person. Hence, BFO has class "Role" as a subclass of "Specifically dependent continuant". Then, a question may arise as to whether man and woman are really subclasses of person or just roles that person can have. But, from the point of learning, it is not important to distinguish roles from subclasses. To learn more details of a learning item, it often happens that some portion of the learning item is learnt more, and both classifications are important. So, in EduGraph ontology, both man and woman, and lawyer and teacher are subclasses of person. But to distinguish between them, a subclass relationship can have a name. Since man and woman are subclasses of person from the point of gender, these subclass relationships are named "by gender", and since lawyer and teacher are subclasses from the point of profession, these subclass relationships are named "by profession”. There are several 
more simplifications and modifications, and in consequence, class hierarchy of the upper ontology of EduGraph ontology becomes as shown in Fig. 3.

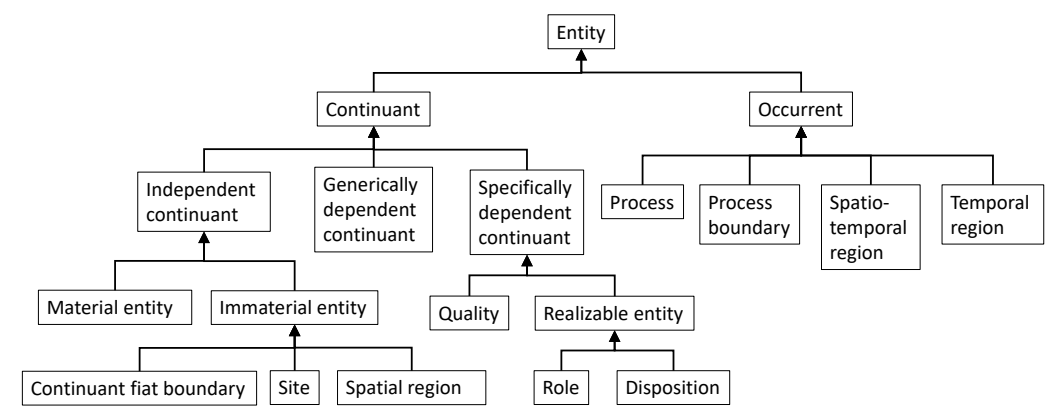

Fig. 2. Upper part of BFO

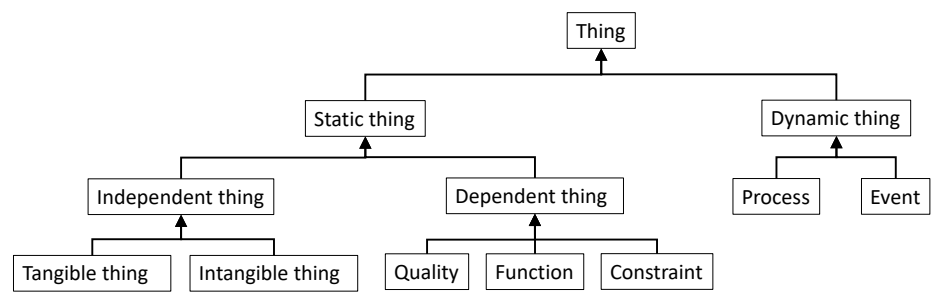

Fig. 3. Upper ontology of EduGraph ontology

\section{Tentative Evaluation through Actual Applications}

\subsection{Application to "Introduction to Information Technology” in 2015}

From 2015, at a university that one of the authors works for, EduGraph is actually used in some of introductory courses. "Introduction to Information Technology" is one of the courses that EduGraph were first used in 2015.

Course Explanation. It is an introductory course for freshmen, and covers basics on information technology, all of which are necessary to understand subsequent courses on information technology. In Japan, some high schools provide a similar course and some not. Hence, students' backgrounds for this course differ, but its goal is the same.

How EduGraph Was Applied. The contents of this course are fairly standardized and the contents in 2015 and in 2014 are almost the same, except that the slides in 2015 were prepared in Markdown, not in PowerPoint as in 2014, and that the contents in 2015 were structured by EduGraph ontology.

The course was taught at a classroom equipped with a computer for each student. At the first class, all slides for the course structured by EduGraph ontology were provided to all students. For each class, students were requested to self-study the slides using EduGraph before the class and after the class. When they did not 
understand a learning item, they did backward learning, navigated by EduGraph ontology. Students were also requested to submit a minute paper of their self-studies. In a classroom, a teacher used the slides as ordinal slides, but more time was spent to explain items on which students raised questions and in which students expressed a special interest at the minute papers. Fig. 4 is some screen shots of EduGraph and shows the relation between EduGraph ontology and slides.

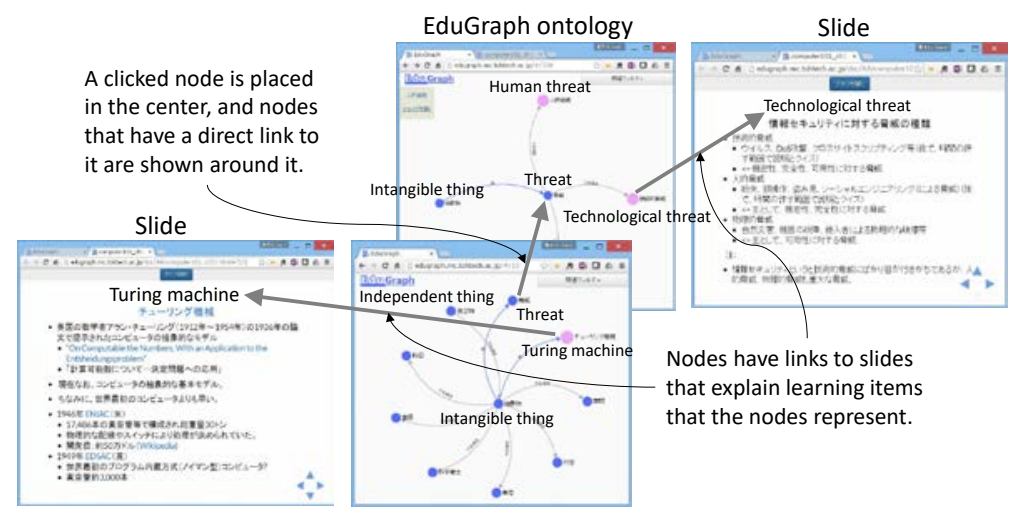

Fig. 4. Some screen shots of EduGraph

Results. Fig. 5 is a histogram of the exam scores in 2014 and in 2015. Since most of the questions of the exams are 4 answer choice questions, scores less than or equal to 25 means that they did not learn at all. Regrettably, about $10 \%$ are such students both in 2014 and also in 2015. Except them, the portion of poor students (scores between 26 and 50) becomes less than $40 \%$ in 2015 , compared to more than $50 \%$ in 2014 . The portion of good students (scores more than 75) increased significantly in 2015, compared to in 2014. Table 2 shows some overall statistics of the exam scores in 2014 and in 2015. The average score in 2015 is 7 points higher than that in 2014 (p = 0.021). Since this comparison is not based on a properly designed experiment, it cannot be concluded that this improvement is achieved mainly by EduGraph, and is significant, even with $\mathrm{p}=0.021$. But still, the result suggests that EduGraph is effective. Unfortunately, it also suggests that EduGraph is not successful for motivating students who will not study. For more details please refer to our previous paper [22].

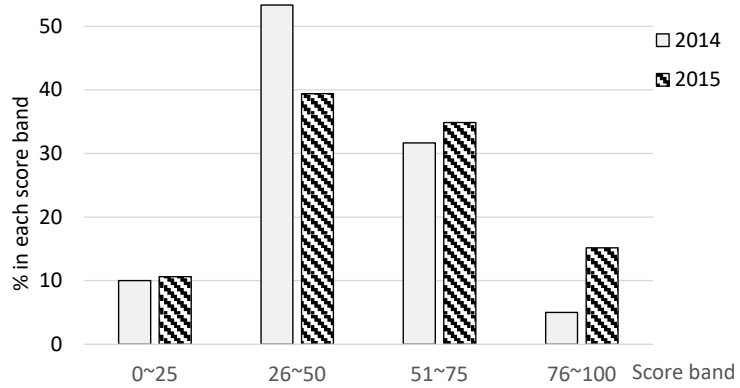

Fig. 5. Histogram of exam scores in 2014 and in 2015 
Table 2. Some statistics of exam scores in 2014 and in 2015

\begin{tabular}{lllcl}
\hline \hline & 2014 & 2015 & $\begin{array}{c}\text { Diffrence } \\
(2015-2014)\end{array}$ & Note \\
\hline Number of Students & 60 & 66 & 6 & \\
Mean & 44.4 & 51.4 & 7.0 & $\mathrm{t}=2.03, \mathrm{P}(\mathrm{T}>\mathrm{t})=0.021$ \\
Standard Deviation & 18.1 & 20.2 & 2.1 & $\mathrm{f}=1.25, \mathrm{P}(\mathrm{F}>\mathrm{f})=0.194$ \\
\hline \hline
\end{tabular}

\subsection{Other Applications and Discussion}

Currently, several introductory courses use EduGraph, including "Introduction to Information Technology” in 2016. The authors feel that EduGraph gradually becomes more effective as experiences and know-how on using EduGraph are accumulated. However, the portion of students who will not learn hardly decreases, although students somewhat motivated learn more with EduGraph. In addition, even excluding these students, it is not clear why students learn more with EduGraph. Hopefully, EduGraph may generate intrinsic motivation. But, in the courses that use EduGraph, teachers encourage students to learn by themselves outside a classroom, using EduGraph. This may generate extrinsic motivation.

If EduGraph is successful for generating intrinsic motivation by showing a shortterm goal and learning items to be learnt backward, it is not clear how far it is effective. For example, suppose that a student does not understand learning item A, and that he or she learns learning item $B$ that is necessary to understand learning item A. But unfortunately, if he or she does not understand learning item B either, he or she has to learn learning item $C$ and so on. It is not clear what depth of this recursiveness can keep his or her intrinsic motivation to understand learning item $\mathrm{A}$.

\section{$6 \quad$ Summary and Future Works}

This paper has proposed EduGraph, an ontology-based backward learning support system, which intends to respond to the difficult situation that students with different academic skills need to achieve the same goal.

Similar to preparing slides in PowerPoint, a teacher can prepare slides using EduGraph. In a classroom, a teacher can use them as ordinal slides, and, outside a classroom, students can use them by their own smartphones or PCs. EduGraph ontology, based on a well-designed upper ontology, structures all learning items on slides. Navigated by EduGraph ontology, each student sets his or her own short-term goal and learn it backward, motivated intrinsically.

Our experiences from 2015 suggest that EduGraph is effective. We will continue to achieve good results, applying EduGraph to more introductory courses, and will also make an objective experiment that evaluates how much and in what way EduGraph is effective.

Acknowledgments. A part of this research is supported by the Japan Society for the Promotion of Science KAKENHI Grant Number 15K12423. 


\section{References}

1. Ryan, R. M., Deci, E. L.: Intrinsic and extrinsic motivations: Classic definitions and new directions, Contemporary educational psychology 25(1), 54-67 (2000)

2. Stipek, D.: Motivation to Learn from theory to practice, third edition, Allyn \& Bacon, MA (1998)

3. Wiggins, G. P., McTighe, J.: Understanding by design, ASCD, VA (2005)

4. Backwards Learning Organizer, http://www.thoughtfulclassroom.com/tools/PDFs/ Backwards_Learning_Organizer.pdf, last accessed 2017/1/21

5. Sasaki, T.: An Examination of Studies Based on Backward Reasoning in High School Mathematics (in Japanese), Bulletin of Tokyo University and Graduate School of Social Welfare, 5(2), 103-108 (2015)

6. Novak, J. D., Alberto J. C.: The theory underlying concept maps and how to construct and use them, Technical Report IHMC CmapTools 2006-01 Rev 01-2008 (2008).

7. Ausubel, D. P.: Educational psychology: A cognitive view, Holt, Rinehart and Winston, NY (1968)

8. Chu, K.-K., Lee, C.-I., Tsai, R.-S.: Ontology technology to assist learners' navigation in the concept map learning system, Expert Systems with Applications 38(9), 11293-11299 (2011)

9. Gruber, T. R.: A translation approach to portable ontology specifications, Knowledge acquisition 5(2), 199-220 (1993)

10. Snae, C., Brueckner, M.: Ontology-driven e-learning system based on roles and activities for Thai learning environment, Interdisciplinary Journal of Knowledge and Learning Objects, 3, 1-17 (2007)

11. Gaeta, M., Orciuoli, F., Ritrovate, P.: Advanced ontology management system for personalized e-learning, Knowledge-Based System, 22, 292-301 (2009)

12. Baker, E. L.: Ontology-based educational design: seeing is believing, Resource Paper 13, National Center for Research, Graduate School of Education, University of California, Los Angeles (2012)

13. Muroya, D., Hayashi, Y., Seta, K.: LOD-Based Support for Self-Exploratory Learning in History (in Japanese), The Japanese Society for Artificial Intelligence, SIG-ALST-B50404, 17-21 (2016)

14. Smith, B.: Basic Formal Ontology 2.0 Specifications and User’s Guide, https://github. com/BFO-ontology/BFO/raw/master/docs/bfo2-reference/BFO2-Reference.pdf, last accessed 2017/1/10

15. DOLCE: a Descriptive Ontology for Linguistic and Cognitive Engineering, http://www.loa.istc.cnr.it/old/DOLCE.html, last accessed 2017/1/15

16. Suggested Upper Merged Ontology (SUMO), http://www.adampease.org/OP/, last accessed 2017/1/15

17. Sowa, J. F.: Top-Level Categories, http://www.jfsowa.com/ontology/toplevel.htm, last accessed 2017/1/21

18. Mizoguchi, R.: YAMATO: Yet Another More Advanced Top-level Ontology, http://download.hozo.jp/onto_library/ YAMATO101216.pdf, last accessed 2017/1/10

19. Apr, R., Smith, B., Spear, A. D.: Building Ontologies with Basic Formal Ontology, The MIT Press, MA (2015)

20. Markdown Here, http://markdown-here.com/, last accessed 2017/1/10

21. Neo4j, http://neo4j.com/, last accessed 2017/1/10

22. Okabe, M.: Ontology-Navigated Tutoring System for Flipped-Mastery Model, Proceedings of The ICALT 2016: 18th International Conference on Advanced Learning Technologies 18(10), 1814 - 1820 (2016) 